\title{
Some comments on thickened tailings and beach slopes
}

\author{
TG Fitton Fitton Tailings Consultants, Australia
}

\begin{abstract}
This paper discusses a number of points on the related topics of thickened tailings and beach slopes. Such points include the claim that thicker tailings is required in order to achieve steeper beach slopes, the claim that fan slopes dictate beach slopes, and the relevance of the segregation threshold. The paper discusses these points and others, and presents evidence to clarify the facts. Some relevant real world cases are also presented and discussed. Finally, some attention is given to the application of Robinsky's thickened discharge concept to unthickened tailings, which thereby avoids the dam failure risks that plague conventional tailings disposal.
\end{abstract}

Keywords: thickened tailings, beach slope, tailings storage facility

\section{Introduction}

Eli Robinsky's concept of thickened tailings disposal has been applied at dozens of mines around the world since it was first proposed some 50 years ago. The defining aspect of Robinsky's concept is the exploitation of the beach slopes that are generated by the discharge of a tailings slurry, in order to reduce embankment volumes and reduce the risk of dam failures (Robinsky 1978).

This paper seeks to clarify some popular misconceptions about thickened tailings and beach slopes, and even challenge some of the established conventions in the field.

The questions that are considered include:

- Is thicker tailings slurry required in order to achieve steeper beach slopes?

- Do fan slopes dictate beach slopes?

- How relevant is the segregation threshold?

The paper discusses these points and others, and presents evidence to clarify the facts. Some relevant real world cases are also presented and discussed. Finally, some attention is given to the application of Robinsky's thickened discharge concept to unthickened tailings, which thereby avoids the dam failure risks that plague conventional tailings disposal.

\section{Thicker tailings for steeper beach slopes}

There is a popular belief that higher density thickener underflow is needed in order to achieve steeper beach slopes. Whilst thicker tailings slurry does yield steeper beaches, lower flow rates have a more dramatic impact on achieving steeper beaches. This is best illustrated with a graph showing the relationship between the beach slope, slurry concentration and discharge rate. Such a graph, for a particular gold tailings slurry, is presented as Figure 1. A family of curves is shown for a range of tailings slurry concentrations, with the $y$-axis indicating the resultant beach slope, and the $x$-axis plotting the tailings discharge rate. This family of curves has been generated using one of the beach slope models presented by Fitton (2007), which was calibrated with flume data gathered at the particular gold mine in question. It is noted that whilst other tailings slurries may generate different beach slopes at a given concentration or discharge rate, all tailings beach slopes steepen when the slurry concentration is increased, or when the discharge rate is diminished. 


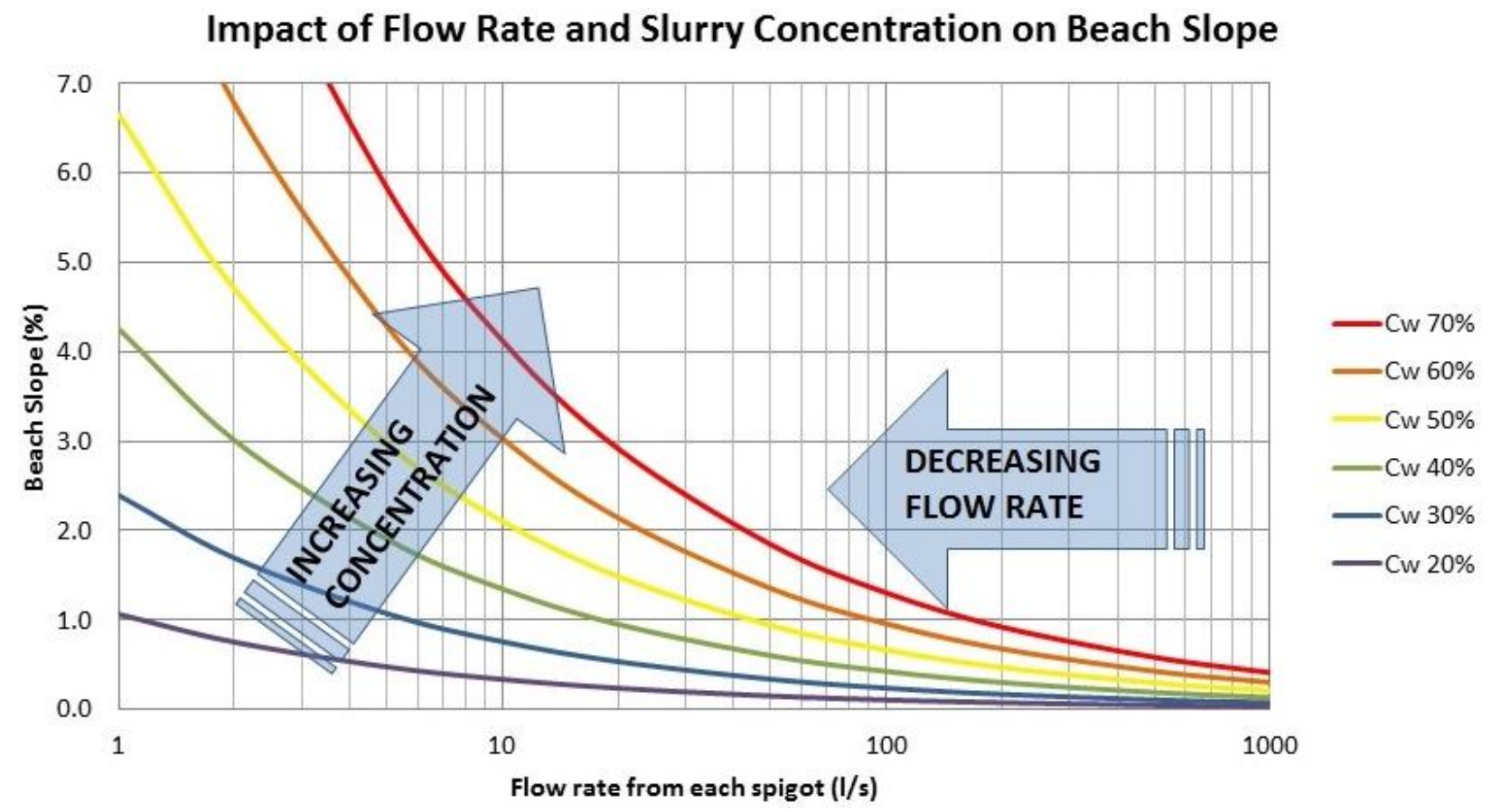

Figure 1 Predicted beach slopes for a gold tailings slurry, illustrating the impact of changing the flow rate or solids concentration. The $\mathrm{Cw}$ figure is the slurry concentration by weight

From Figure 1 it can be seen from the concentration associated with each curve that an increase in the slurry concentration will indeed result in steeper beach slopes, but reducing the flow rate (by splitting the flow) also has a steepening effect. To describe a practical example of this, assume that the gold mine featured in Figure 1 is discharging a single stream of tailings onto a central thickened discharge (CTD) tailings storage facility (TSF) at a concentration of $60 \%(\mathrm{w} / \mathrm{w})$ and a flow rate of $200 \mathrm{l} / \mathrm{s}$. Figure 1 indicates that this combination of flow rate and concentration would produce a beach slope of about $0.7 \%$.

For reasons of limited available land and minimisation of embankment raising, the mine operator wishes to increase the beach slope. One way to steepen the beach would be to thicken the slurry to $70 \%$ solids. This would increase the slope to about $0.9 \%$, but the cost of this additional thickening could be of the order of millions of dollars, as it is quite possible that the existing thickener may not be able to achieve the target underflow density, thereby necessitating the procurement of a different type of thickener. The other way to steepen the beach slope would be to split the flow. If the flow was split into two streams, the beach would steepen to about $1.0 \%$, providing the two slurry streams don't merge on the tailings beach. If the flow could be split into 10 streams without the channels merging on the beach, the beach slope would increase to about $2.1 \%$, without any additional thickening required. It is expected that this flow splitting option will be far cheaper and quicker to achieve than thickening the slurry to a higher concentration. It is also asserted that it is likely that the reliability of the split flow operation will be superior to the high-concentration alternative, given that the thickener is already producing the $60 \%$ concentration underflow.

It should be noted, however, that the splitting of the flow provides some steepening, but within limits. An infinite number of splits is not possible, as the streams will merge on the beach, thereby negating the impact of the split. Fitton (2016) presented a method for spacing discharge points to manage the merging of flows and achieve reasonably targeted beach slopes. Furthermore, some tailings slurries simply create flatter beach slopes than others, even at relatively high concentrations and low flow rates. The accuracy of the initial beach slope prediction is still of prime importance in the initial design of a thickened tailings storage facility. A comparison of the predictive accuracy of various published beach slope prediction models was presented by Fitton $(2007,2014)$.

In the Fitton (2016) paper, optimisation of the spigot spacing method led to the concept of a truncated CTD being presented. Following the publication of the Fitton (2016) paper, it was raised to the author's 
attention that a truncated CTD was already operating at the Sunrise Dam Gold Mine in Western Australia. This TSF had been operating as a 'pointy' CTD for some years, but in an effort to steepen the beach slope, the mine owner had incrementally moved towards greater splitting of the flow, and eventually developed a 'tabletop' on their CTD in order to minimise the merging of channels on the beach. As a result of that truncation, the Sunrise Dam TSF is now achieving beach slopes of about $4 \%$. A topographic plan of the Sunrise Dam CTD is presented in Figure 2, showing the truncated top and the steeper beach slopes.

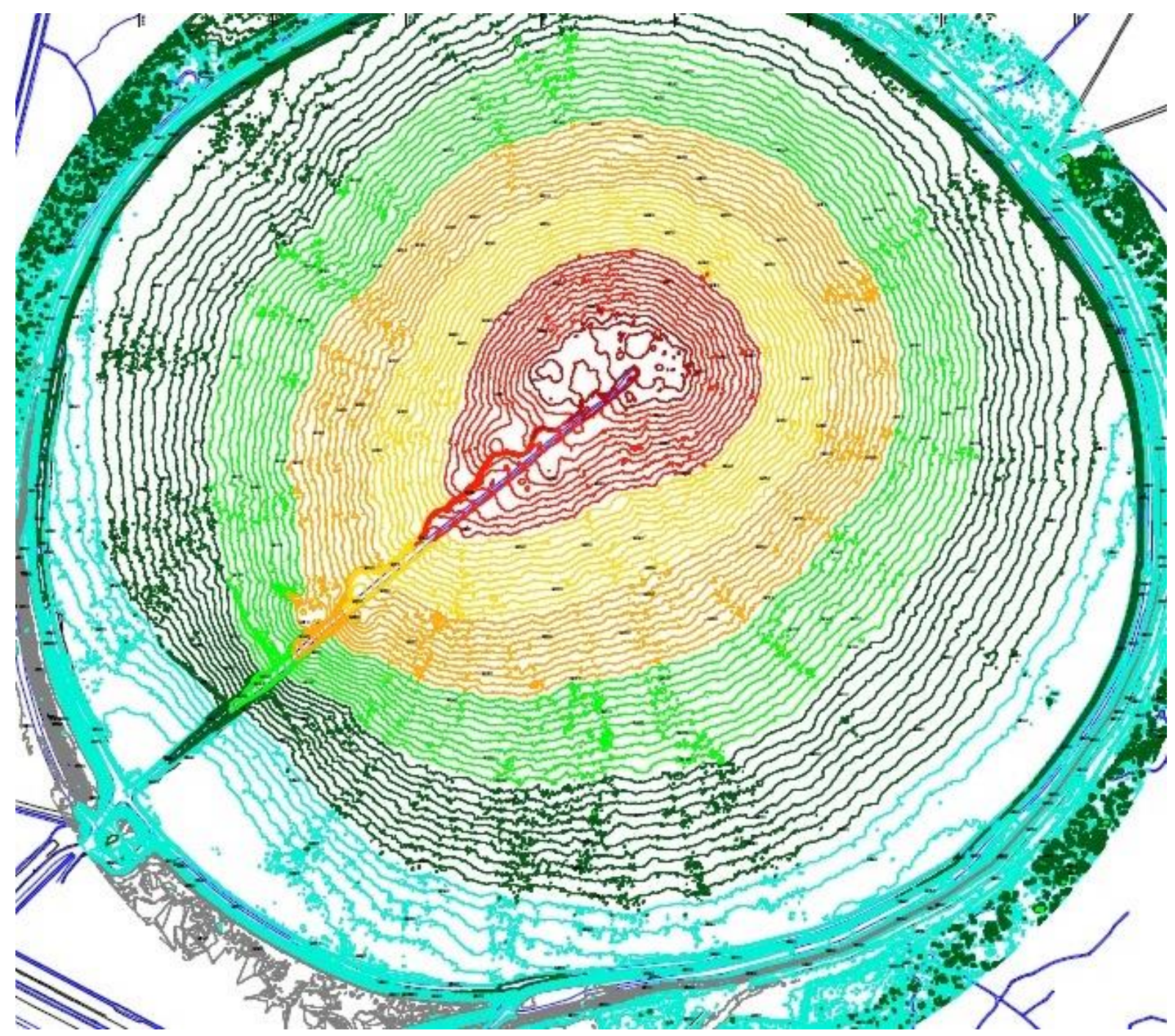

Figure 2 Sunrise Dam CTD in 2016. The contour interval is $0.5 \mathrm{~m}$. The diameter of the CTD is about $2 \mathrm{~km}$. Note the flat top, which is about $250 \mathrm{~m}$ wide and $150 \mathrm{~m}$ long

The Peak gold mine in Cobar has also proceeded along a similar route of splitting flows in order to achieve steeper beach slopes, but instead of operating their CTD with a truncated top for spacing the discharge spigots effectively, a linear ridge was constructed down the middle of the stack, with a number of spigots operating along each side. At that mine, the linear ridge was more practical than a circular truncation because of the oblong shape of the CTD. This practice has successfully increased the beach slopes at Peak to about $8 \%$. A photograph of the Peak CTD, taken in 2016, is presented as Figure 3. 


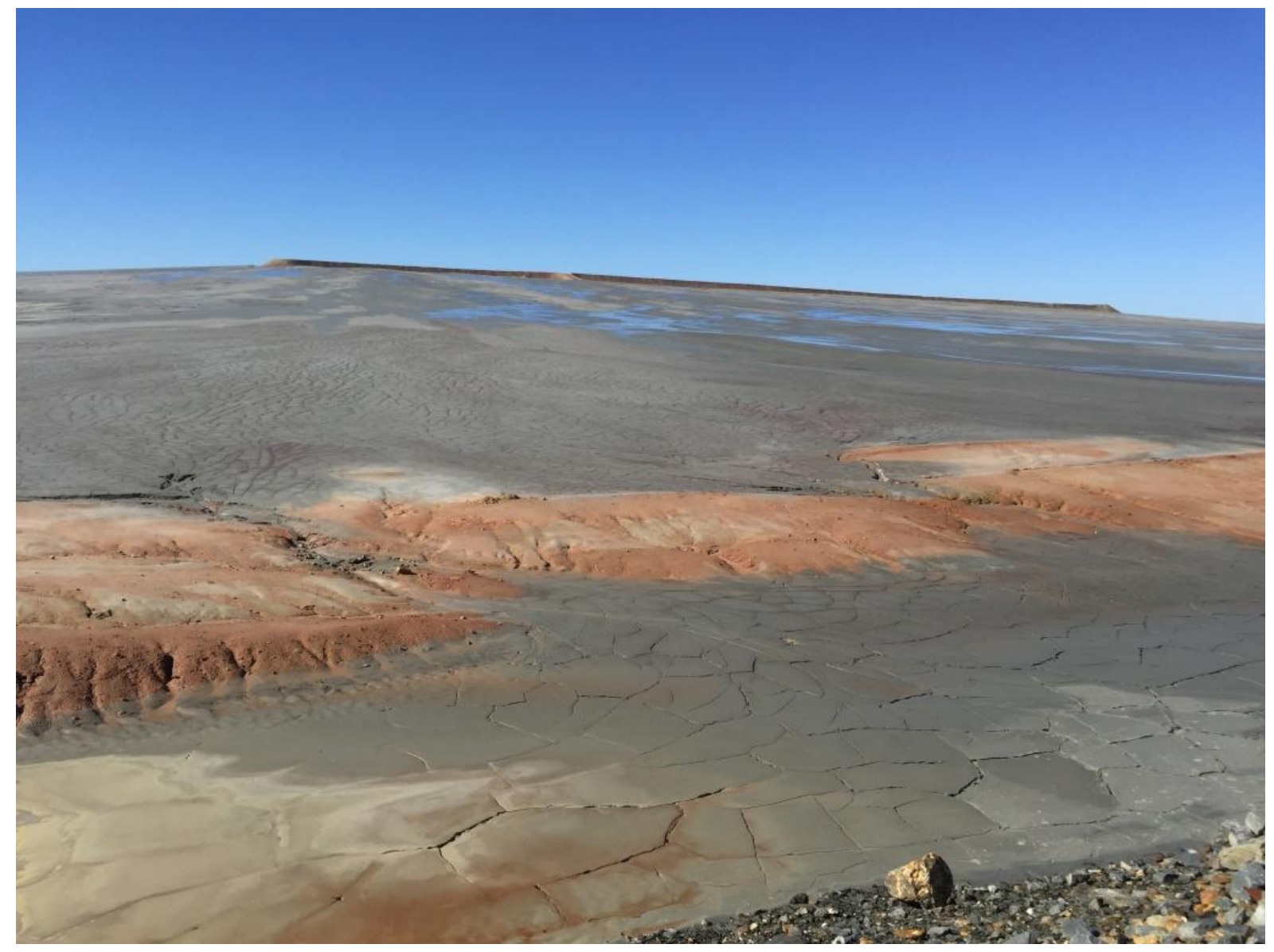

Figure 3 Peak CTD in 2016 - note the 'spine' running along the top of the stack

The two examples of Sunrise Dam and Peak provide a good demonstration of the practical advantage of splitting flows to achieve steeper beach slopes. It is asserted that thickening alone, without splitting the flow, would not have generated slopes as steep. It is also asserted that the thickening option would have been more expensive in both cases.

\section{$3 \quad$ Fan slopes, channel slopes and beach slopes}

On a tailings beach, typically the tailings slurry emerges from a pipe to fall into a turbulent plunge pool. At some point on the perimeter of the plunge pool, an open channel of slurry flows forth. This channel typically runs for hundreds of metres before the flow spills out into fan flow (or sheet flow as it is also called). The fans are always shallower and wider than the channel, with lower velocities. The fans also have steeper slopes than the channels. The lower velocities in the fans allow the tailings particles to settle onto the tailings beach, thereby resulting in new deposition in the tailings storage. Eventually, the channels run over the top of the fans to deliver slurry to other more distant areas on the beach (Fitton 2007).

It has been asserted that the slope of the fan flow on a tailings beach is what dictates the beach slope (Simms 2007; Simms et al. 2011). Others have suggested that the fan slope as well as the channel slope is what dictates the resultant overall beach slope (Wates et al. 2015; Li 2011; Covacevich et al. 2013).

It is argued that the fan slope is largely irrelevant in the prediction of the overall beach slope, since the fan slopes only make up a relatively small part of the overall slope of the beach, which the channels eventually overrun. By this process, it is the channel slope that dictates the overall beach slope. In order to predict the beach slope, it is only the channel slope that needs to be predicted. Williams and Meynink (1986) were the first to arrive at this conclusion, but others have also asserted the same tenet since then (McPhail 1995; Pirouz et al. 2005; Chryss et al. 2006; Fitton 2007). 
The exception to this is when a tailings deposit is so small that channels have not yet formed. This is where the sheet flow assumptions applied by Simms (2007) prove to be valid, and indeed the slope prediction model presented by Simms (2007) proves to be quite accurate. However, such tailings deposits might only exist for a few minutes in a full-scale tailings discharge scenario. In a typical tailings deposit that is hundreds of metres long (or greater), channel flow always occurs.

\section{$4 \quad$ Segregation threshold}

There is some consensus among practitioners in the field that a tailings slurry needs to be thickened beyond the segregation threshold in order for a Robinsky-style thickened discharge storage facility to work. Indeed Professor Robinsky himself claimed this (Robinsky 1978). There is also a general consensus that the discharge of a segregating tailings slurry will result in a high degree of concavity in the initial part of the beach, with relatively flat beach slopes trailing outwards for the greater distance to the pond.

This paper raises some compelling evidence to suggest that a slurry does not necessarily need to be thickened beyond the segregation threshold in order for exploitable beach slopes to be created. It also presents some surprisingly linear and steep beach profiles that were created by the discharge of segregating slurries.

\subsection{Example 1: Siilinjärvi}

As one example, the case of the Siilinjärvi mine is described. This apatite mine in Finland had been operating with conventionally thickened tailings for some 35 years, but with the slurry discharge from an elevated causeway, like a CTD. The Siilinjärvi TSF is about $4.5 \mathrm{~km}$ in length, with a maximum width of about $2.5 \mathrm{~km}$. A 2003 aerial photograph obtained from Google Earth (presented as Figure 4) shows a tailings beach that would appear to be a CTD. However, at the time the tailings slurry was being discharged at a concentration of $45 \% \mathrm{w} / \mathrm{w}$, which was well below the segregation threshold.

Up until 2016, the Siilinjärvi tailings exhibited the following physical characteristics:

- Concentration (by weight) was typically $45 \%$.

- Solids specific gravity -2.84 .

- Approximately $65 \%$ of the solids (by weight) are mica flakes.

- Particle size distribution (PSD) $-D_{15} 35 \mu \mathrm{m}, \mathrm{D}_{50} 250 \mu \mathrm{m}$, and $\mathrm{D}_{85} 600 \mu \mathrm{m}$.

- $\mathrm{pH}$ - approximately 10.

The coarse grading of the tailings particles has a major impact on the behaviour of the slurry, not only with respect to the rheology and transport of the slurry, but also in regard to its segregation characteristics.

Some topographic survey of the TSF from the year 2010 was obtained from the mine owner. This is presented as Figure 5. It can be seen that the conical deposit that was evident in the 2003 aerial photograph had been partially buried beneath a new conical deposit discharged from further south, but a substantial portion of the first cone remained exposed. A cross-section was taken along the profile of this beach, as shown in Figure 5. The cross-section is presented as Figure 6. 


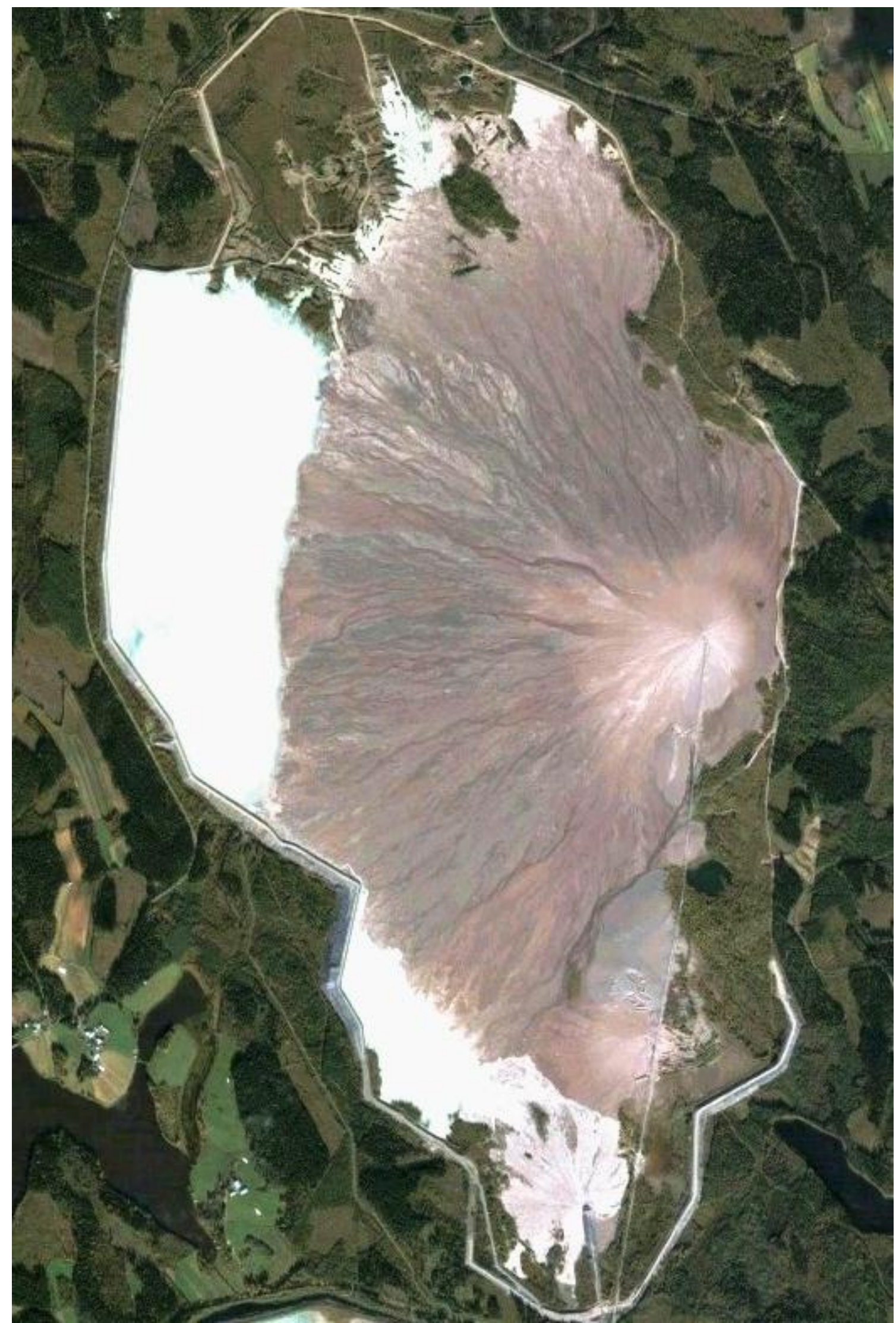

Figure 4 Aerial photograph of the Siilinjärvi TSF, taken in 2003 


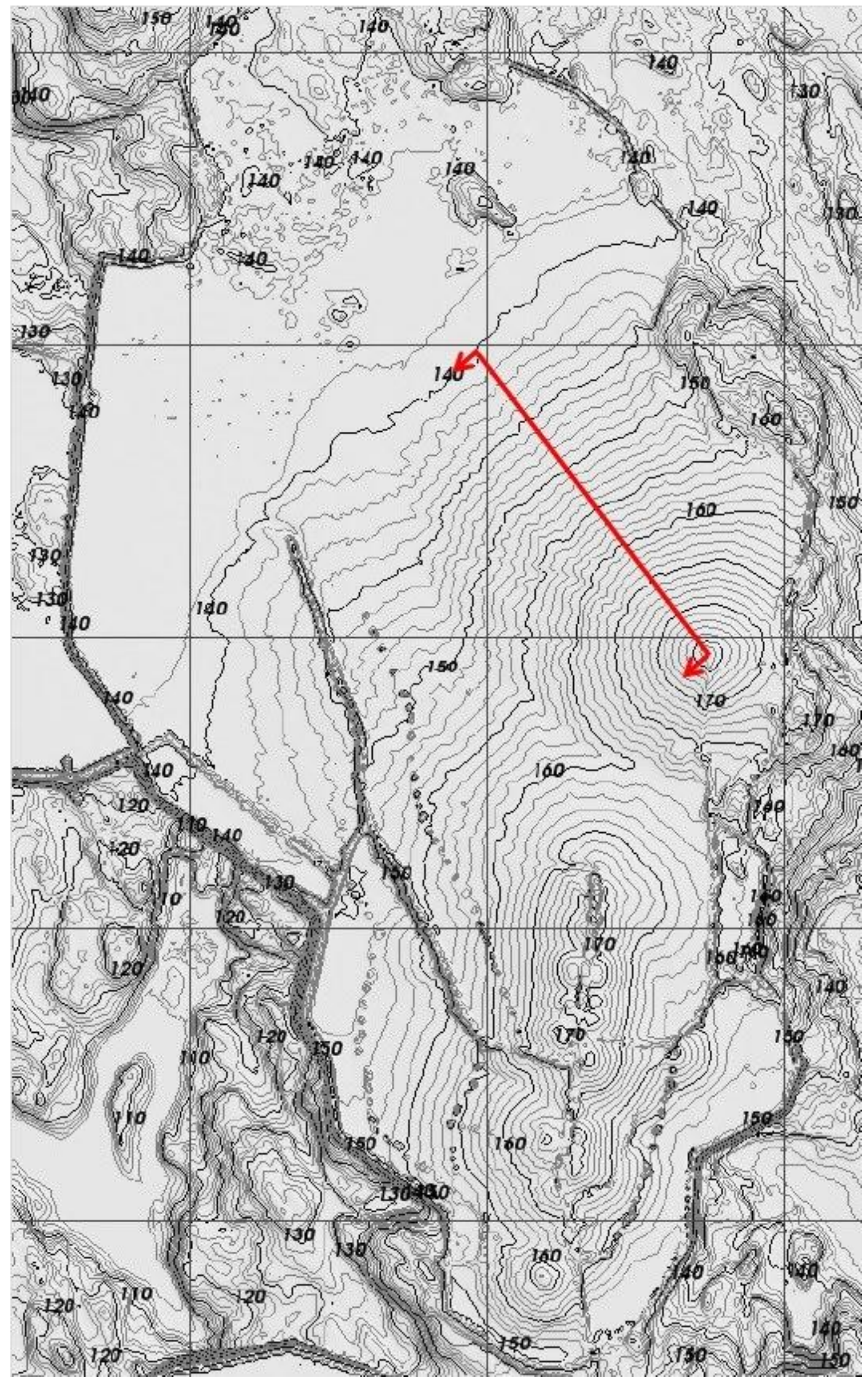

Figure 5 Topographic contours of the Siilinjärvi TSF in 2010, with the section line shown in red 


\section{Section through 2010 Siilinjärvi cone}

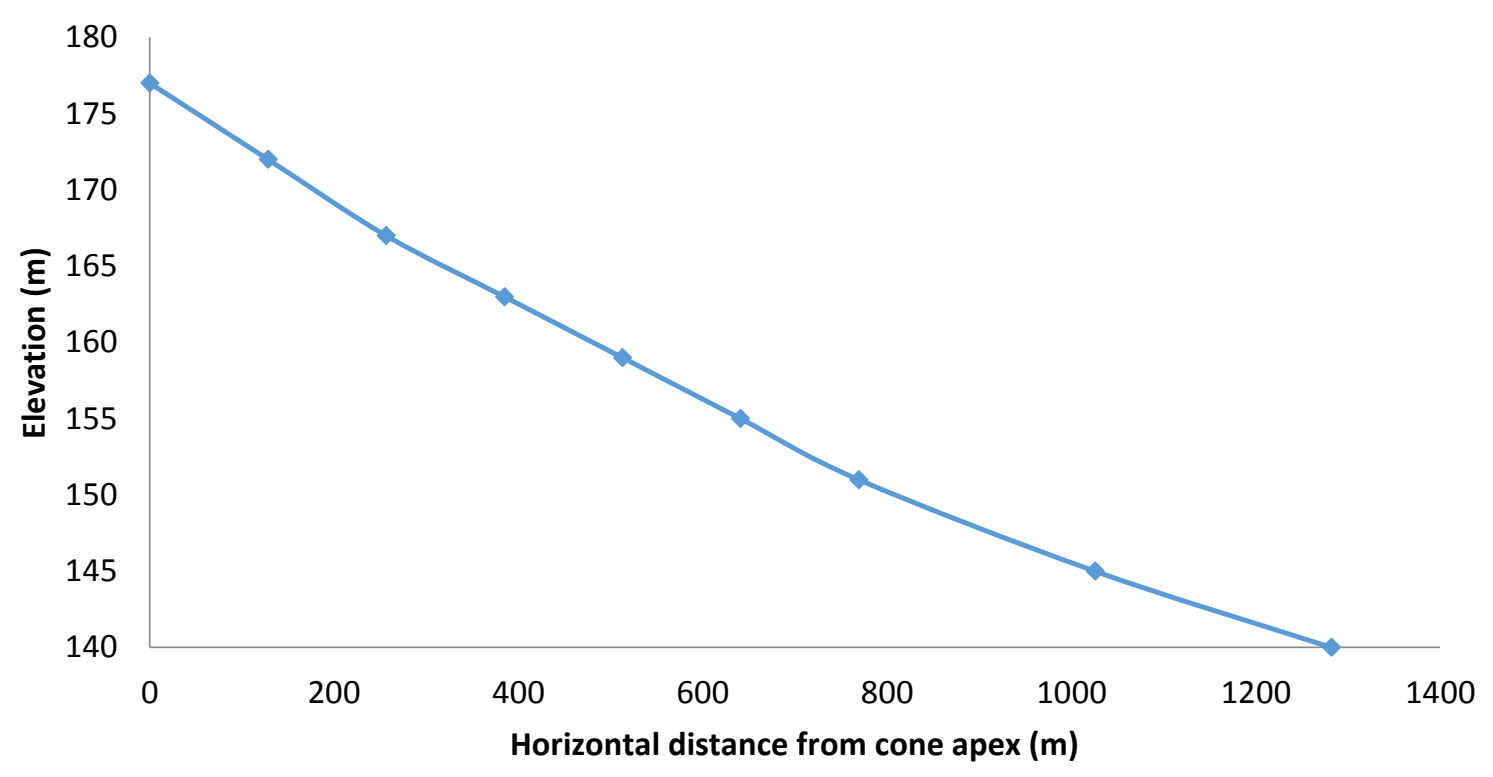

Figure 6 Cross-section through the 2010 Siilinjärvi TSF surface

The Siilinjärvi beach profile presented in Figure 6 exhibits beach slopes of $3.9 \%$ for the upper $250 \mathrm{~m}$ length of the beach, and an average slope of $2.9 \%$ for the upper $1,220 \mathrm{~m}$ of its length. These are relatively steep slopes in comparison to most tailings beaches, even considering those of thickened tailings deposits. Also noted is the remarkably linear profile, considering the segregation that one would expect to see with such a coarse slurry being discharged at the relatively low concentration of $45 \%$ solids $(w / w)$.

Indeed segregation (or hydraulic sorting) has often been attributed as the cause of concavity in tailings beaches, but the cross-section presented in Figure 6 exhibits less concavity than many non-segregating tailings beaches do.

\subsection{Example 2: Whipple et al. (1998)}

Another example of steep and relatively linear beach slopes deposited by segregating slurry is discussed here; that being the case of the alluvial geology experiments presented by Whipple et al. (1998). These geologists carried out a series of laboratory experiments to investigate the formation of alluvial fan deposits. They formed small-scale fan deposits in a laboratory by discharging dilute slurries onto a flat floor at the intersection of two vertical surfaces to produce a deposit resembling the quadrant of a cone. The solid particles settled on the floor and stacked up over time, in a similar manner to the formation of tailings deposits. These workers noted the existence of channel flow occurring on the surface of the deposit, with the channel periodically changing its course, again similar to the channel flow behaviour observed on tailings beaches. A weir defined the outer extents of the experimental deposition area, enabling the slurry flow to be left running long enough for the deposit to develop a stable profile through the processes of erosion and deposition taking place simultaneously, with the overflow running over the weir. Fifty-one such runs featuring coal and sand slurries were presented, with solids volumetric fractions of the slurries varying between 0.0066 and 0.063 , discharge rates varying from 0.11 to $0.48 \mathrm{l} / \mathrm{s}$, median particle sizes ranging from 70 to $550 \mu \mathrm{m}$ and particle densities ranging from 1,350 to $2,650 \mathrm{~kg} / \mathrm{m}^{3}$. Average beach slopes observed ranged from 0.8 to $13 \%$. Two deposition areas were used, with one having the weir set at a radius of $2.1 \mathrm{~m}$ from the discharge point, and the other set at a radius of $5.2 \mathrm{~m}$. A diagram illustrating the experimental setup is presented as Figure 7. 


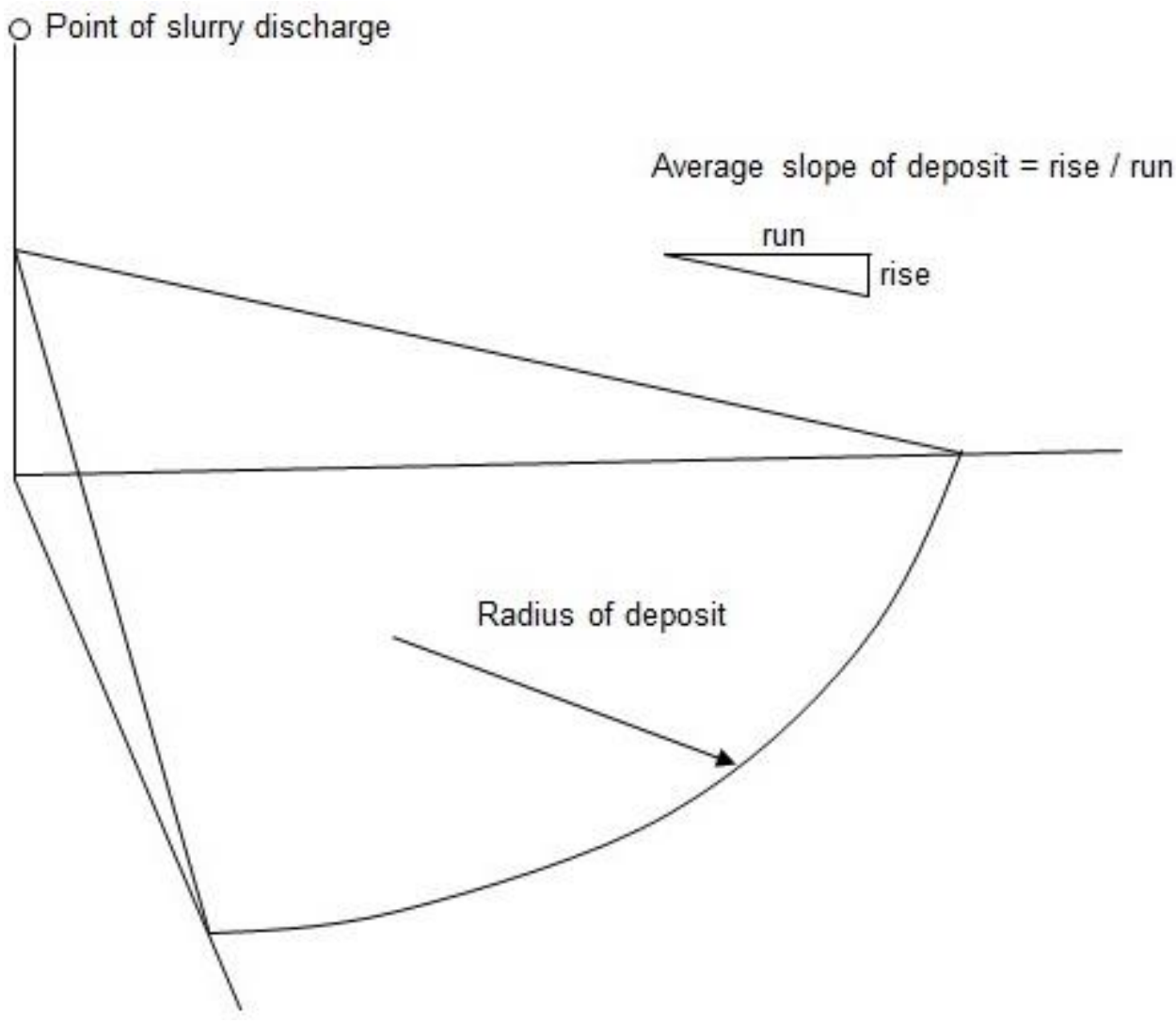

Figure 7 Diagram of the Whipple et al. (1998) experiments

Cross-sections along the deposit profiles were presented in the Whipple et al. (1998) paper. Some of these have been reproduced in Figure 8.

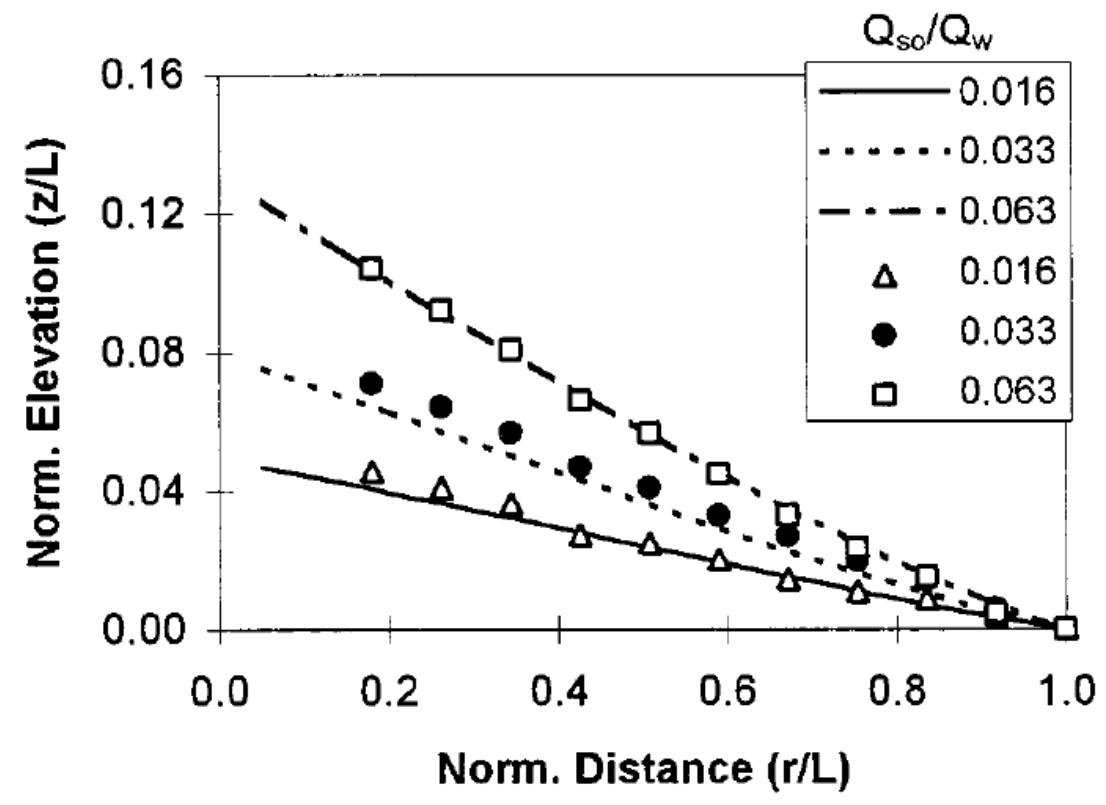

Figure 8 Some measured deposit profiles from the Whipple et al. (1998) experiments. ' $\mathrm{Q}_{\text {so }} / \mathrm{Q}_{\mathrm{w}}$ ' refers to the ratio of the solids volumetric flow rate to the water flow rate

It is noted that the deposit profiles presented in Figure 8 exhibit surprisingly linear slopes, even though the slurry was most definitely well below the segregation threshold, with the most concentrated slurry tested having a volume fraction of only 0.063 (about $15 \%$ by weight). The very steep slopes measured are due to 
the very low flow rates tested $(0.11$ to $0.48 \mathrm{l} / \mathrm{s})$. Such slurries would produce far flatter beach slopes at the much higher flow rates that are encountered at typical tailings storage facilities, but this in itself illustrates the impact on beach slopes that reducing the flow rate has.

In 2007, Fitton recognised that beach slopes still formed with segregating slurries, and he presented an $a$ priori model for predicting such beach slopes. That model predicted the beach slopes from the Whipple et al. (1998) experiments quite well, along with other relevant beach slope data created with the discharge of other segregating slurries.

\subsection{Is segregation a show-stopper?}

Both the Siilinjärvi tailings deposit and Whipple et al. experiments demonstrate that in some cases, segregating slurries can produce deposits with steep and relatively linear beach slopes. This flies in the face of the common beliefs about segregating tailings, and suggests that there is more to the story. It is therefore apparent that more research is needed on the topic of segregating tailings.

Tailings deposition is essentially an alluvial delta formation, whether the slurry is segregating or not. Although it has been observed that the beach slopes and the degree of concavity vary considerably from one case to the next, it is asserted that the flow rate and the PSD are more critical than the segregation threshold in this regard.

\subsection{An alternative storage strategy for all tailings slurries}

Considering the number of dam failures of tailings storages in the past, there is a strong argument here to suggest that we should operate all TSFs with a separate dam for the water (in a similar way to that proposed by Robinsky for thickened tailings), rather than the conventional (high risk) option of allowing the water pond to sit on top of the tailings. Of course the beach slope may be much flatter than those examples presented here, and the degree of concavity might be much greater, but the tailings surface could still be exploited for improved dam safety and possible cost advantage. This result could be achieved by beaching the tailings towards a filter dam, allowing the water to run through it to its own separate storage facility at a lower level. The main benefit of this approach is the ability to remove the pond from on top of the tailings, thereby enabling the storage facility to contain a much lower volume of saturated tailings. This will result in a more stable tailings deposit in the event of a dam failure after an earthquake or overtopping event. It is also possible that the two smaller dams will require less construction material than one taller one, so this approach might also result in lower storage construction costs.

\section{A general comment about thickener operation}

This paper has demonstrated that lower concentration slurries can achieve relatively steep beach slopes in certain circumstances, but it is acknowledged that this is not typical. There are many mining operations endeavouring to thicken the tailings well beyond the segregation threshold in an effort to recover the most water possible, but in some cases this is not because of the cost or scarcity of water. Some mines seek to produce the highest possible density of thickener underflow for the purpose of achieving a targeted beach slope, or even simply to achieve a target underflow concentration. In such situations, this approach will most likely lead to frustration and disappointment, since the feed often changes to a less optimal condition, and other factors might also interfere with the process. A more realistic expectation of thickener performance will result in far more stability and reliability in operations. The achievement of steeper beach slopes is more easily achieved through rational splitting of flows, but even this has its limits, as is discussed earlier on.

It must also be stressed that tailings slurries often behave quite differently to one another. If $5 \%$ beach slopes are achieved on one mine site, it is not reasonable to expect that such slopes can be achieved on another, just because the same thickener is installed. 


\section{Conclusion}

This paper has sought to raise a few issues of relevance to the mining industry, and in particular, question some of the established approaches to thickened tailings. It is hoped that three main points have been impressed upon the reader; firstly, that splitting of flows is a far more efficient way to steepen beach slopes compared to increasing the concentration of the tailings slurry. Secondly, that predicting the slope of the fans that form on tailings beaches is not relevant to the prediction of the overall beach slope. Thirdly, that segregation threshold may not be such a relevant parameter in the exploitation of beach slopes for tailings storage. Finally, some suggestions have been presented for improving the safety of dammed tailings storages, and for rationalising the expectations on thickener performance.

\section{Acknowledgement}

The author wishes to thank Yara International ASA and AngloGold Ashanti for making historic data available for publishing. The author also thanks New Gold Inc. for allowing access and photography at the Peak mine.

\section{References}

Chryss, AG, Fitton, TG \& Bhattacharya, SN 2006, 'Turbulent flow of non-Newtonian tailings in self-formed channels on tailings stacks', Proceedings of the Ninth International Seminar on Paste and Thickened Tailings, in RJ Jewell, $S$ Lawson and P Newman (eds), Australian Centre for Geomechanics, Perth, pp. 429-438.

Covacevich, J, Wates, J \& Dal Pozzo, S 2013, 'Comparison of predictions of beach slopes using alternative models', in RJ Jewell, AB Fourie, J Caldwell and J Pimenta (eds), Proceedings of the Sixteenth International Seminar on Paste and Thickened Tailings, Australian Centre for Geomechanics, Perth, pp. 481-491.

Fitton, TG 2007, 'Tailings beach slope prediction', PhD thesis, RMIT University, Melbourne (also published as a book by VDM Verlag, Saarbrücken in 2010, ISBN 9783639223729).

Fitton, TG 2014, 'The accuracy of tailings beach slope predictions', in RJ Jewell, AB Fourie, PS Wells and D van Zyl (eds), Proceedings of the 17th International Seminar on Paste and Thickened Tailings, InfoMine Inc., Vancouver, pp. 47-58.

Fitton, TG 2016, 'Thickened tailings discharge: spigot spacing and the merging of streams', in S Barrera and RJ Jewell (eds), Proceedings of the 19th International Seminar on Paste and Thickened Tailings, Gecamin, Santiago, chapter 6.

$\mathrm{Li}, \mathrm{AL}$ 2011, 'Prediction of tailings beach slopes and tailings flow profiles', in RJ Jewell and AB Fourie (eds), Proceedings of the 14th International Seminar on Paste and Thickened Tailings, Australian Centre for Geomechanics, Perth, pp. 307-322.

McPhail, GI 1995, Prediction of the Beaching Characteristics of Hydraulically Placed Tailings, PhD dissertation, University of the Witwatersrand, Johannesburg.

Pirouz, B, Kavianpour, MR \& Williams, MPA 2005, 'Thickened tailings beach deposition. Field observations and full-scale flume testing', in RJ Jewell and S Barrera (eds), Proceedings of the Eighth International Seminar on Paste and Thickened Tailings, Australian Centre for Geomechanics, Perth, pp. 53-72.

Robinsky, El 1978, 'Tailings disposal by the thickened discharge method for improved economy and environmental control', Proceedings of the 2nd International Tailing Symposium, Miller Freeman Publications Inc., San Francisco, pp. 75-91.

Simms, P 2007, 'On the relation between laboratory flume tests and deposition angles of high density tailings', in AB Fourie and RJ Jewell (eds), Proceedings of the Tenth International Seminar on Paste and Thickened Tailings, Australian Centre for Geomechanics, Perth, pp. 329-335.

Simms, P, Williams, MPA, Fitton, TG and McPhail, G 2011, 'Beaching angles and evolution of stack geometry for thickened tailings: a review', in RJ Jewell and AB Fourie (eds), Proceedings of the 14th International Seminar on Paste and Thickened Tailings, Australian Centre for Geomechanics, Perth, pp. 323-338.

Wates, JA, Venter, HA, Dittle, VT \& Cooper, RA 2015, 'Practical observations in beach slope formation and application of the thin layer equilibrium model to observed data', in AB Fourie and RJ Jewell (eds), Proceedings of the Eighteenth International Seminar on Paste and Thickened Tailings, Australian Centre for Geomechanics, Perth, pp. 443-453.

Whipple, K, Parker, G, Paola, C \& Mohrig, D 1998, 'Channel dynamics, sediment transport, and the slope of alluvial fans: experimental study', Journal of Geology, vol. 106, no. 6, pp. 677-693.

Williams, MPA \& Meynink, WJC 1986, 'Tailings beach slopes', Workshop on Mine Tailings Disposal, The University of Queensland, Brisbane. 
